\title{
Early and late results of operations for defects associated with corrected transposition and other anomalies with atrioventricular discordance in a pediatric population
}

\author{
G. Biliciler-Denktas, $M^{\mathrm{a}}$ \\ R. H. Feldt, MD \\ H. M. Connolly, MD \\ A. L. Weaver, MS \\ F. J. Puga, $M D^{\mathrm{d}}$ \\ G. K. Danielson, MD ${ }^{d}$
}

From the Department of Pediatric and Adolescent Medicine, Section of Pediatric Cardiology, ${ }^{\mathrm{a}}$ Division of Cardiovascular Diseases and Internal Medicine, ${ }^{\mathrm{b}}$ Section of Biostatistics, ${ }^{c}$ and Division of Cardiovascular and Thoracic Surgery, ${ }^{\mathrm{d}}$ Mayo Clinic, Rochester, Minn.

Dr Biliciler-Denktas is currently a Fellow in Pediatric Cardiology at the Mayo Clinic, Rochester, Minn.

Received for publication June 29, 2000; revisions requested Aug 24, 2000; revision received Dec 27, 2000; accepted for publication Feb 12, 2001.

Address for reprints: R. H. Feldt, MD, 200 First St, SW, Rochester, MN 55905 (E-mail: feldt.robert@mayo.edu).

J Thorac Cardiovasc Surg 2001;122:234-41

Copyright () 2001 by The American Association for Thoracic Surgery

0022-5223/2001 $\$ 35.00+0 \quad \mathbf{1 2 / 1 / 1 1 5 2 4 1}$

doi:10.1067/mtc.2001.115241
Objectives: The purpose of this study was to determine the early and late results for children having operations for defects associated with corrected transposition of the great arteries and other anomalies with atrioventricular discordance.

Methods: Data on 111 children operated on from July 1, 1971, through January 31, 1996, including clinic records, operative reports, and follow-up visits and questionnaires, were analyzed with particular reference to variables associated with early and late mortality, reoperations, ventricular function, and status of the atrioventricular valves.

Results: Complex associated anomalies were common and included double-outlet right ventricle $(n=43)$ and situs abnormalities $(n=38)$. Overall early mortality was $16 \%$; for the 29 patients operated on after 1986, early mortality was $3 \%$. Early survival was adversely affected by patch repair of ventricular septal defect and early operative interval. Follow-up of the 93 early survivors extended to 26.5 years (mean 11.4 years). Overall survival was $77 \%( \pm 4 \%)$ at 5 years and $67 \%( \pm 5 \%)$ at 10 years. Late survival was adversely affected by prior operations, more severe preoperative functional class, and cardiac rhythm other than sinus. Reoperation was required for $38(41 \%)$ patients, most commonly for conduit replacement $(n=22)$ or repair/replacement of the systemic ventricle atrioventricular valve $(n=13)$.

Conclusions: These results can serve as a basis for comparison with newer surgical alternatives proposed for corrected transposition of the great arteries.

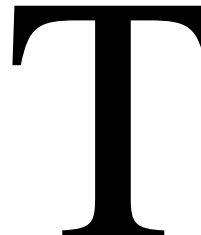

he surgical management of patients with corrected transposition of the great arteries (corrected TGA; atrioventricular discordance with ventriculoarterial discordance) and other anomalies with atrioventricular discordance has been a topic of continued discussion. Previous reports have suggested a pessimistic outlook for patients who have undergone repair of the defects associated with corrected TGA. ${ }^{1-5}$ There has recently been interest in alternative operations that allow the morphologically left ventricle to become the systemic ventricle (SV), such as the "double switch" procedure, modifications of the Rastelli procedure, and modifications of the Fontan operation. ${ }^{6-8}$ Operative results and early follow-up experience of these new operations have been optimistic. ${ }^{6,7}$ However, no intermediate or long-term results of these operations have been published. 
TABLE 1. Associated anomalies

\begin{tabular}{|c|c|}
\hline Anomaly & No. of patients \\
\hline $\begin{array}{l}\text { Atrioventricular discordance with ventriculoarterial } \\
\text { discordance }\end{array}$ & 68 \\
\hline $\begin{array}{l}\text { With situs solitus of viscera and atria and } \\
\text { levocardia }\end{array}$ & 59 \\
\hline $\begin{array}{l}\text { With situs solitus of viscera and atria and isolated } \\
\text { dextrocardia }\end{array}$ & $6^{*}$ \\
\hline $\begin{array}{l}\text { With situs inversus of viscera and atria and dextro- } \\
\text { cardia }\end{array}$ & $2^{*}$ \\
\hline $\begin{array}{l}\text { With situs inversus of viscera and atria and isolated } \\
\text { levocardia }\end{array}$ & $1^{*}$ \\
\hline $\begin{array}{l}\text { Atrioventricular discordance with origin of both great } \\
\text { arteries from the morphologically right ventricle (DORV) }\end{array}$ & 43 \\
\hline $\begin{array}{l}\text { With situs solitus of viscera and atria and isolated } \\
\text { dextrocardia }\end{array}$ & $24^{*}$ \\
\hline With situs solitus of viscera and atria and levocardia & 14 \\
\hline $\begin{array}{l}\text { With situs inversus of viscera and atria and } \\
\text { dextrocardia }\end{array}$ & $3^{*}$ \\
\hline $\begin{array}{l}\text { With situs inversus of viscera and atria and isolated } \\
\text { levocardia }\end{array}$ & $2^{*}$ \\
\hline
\end{tabular}

${ }^{*}$ Considered situs abnormalities

Data on long-term follow-up pertaining to ventricular function for patients with corrected TGA have only been reported in relatively small series. ${ }^{9-11}$ In addition, patients with corrected TGA have survived into adult life, had children, and functioned reasonably well. ${ }^{12-14}$ This subset tends not to have severe impairment caused by associated defects and often has preserved SV function.

The purpose of this article is to present the results of a study of a series of patients with corrected TGA and other anomalies with atrioventricular discordance who were operated on at our institution before 21 years of age and who had repair of the associated congenital cardiac defects. A better understanding of the risk factors for early and late mortality from conventional operations can serve as a basis for comparison with the results of the more recently advocated operations for these anomalies.

\section{Patients and Methods Methods}

Patients selected for this study had corrected TGA with significant associated defects that required repair. These included the distinctive syndrome of atrioventricular discordance, double-outlet right ventricle (DORV), ventricular septal defect (VSD), pulmonary stenosis, and discordant cardiac situs. ${ }^{15,16}$ For simplicity, corrected TGA and the other anomalies with atrioventricular discordance will be grouped together under the term corrected TGA for the remainder of this review. In each instance, patients had biventricular repair in which all defects were repaired. Operations corrected the cardiac defects associated with corrected TGA and used extracardiac conduits from the pulmonary ventricle (PV) to the pulmonary artery when indicated. In each instance, the morphologi-
TABLE 2. Previous procedures

\begin{tabular}{ll}
\hline Procedure & No. $^{*}$ \\
\hline Aortopulmonary connection: (Blalock, Waterston, & 56 \\
Potts, central, or other) & \\
Pulmonary artery banding & 9 \\
Coarctation repair & 4 \\
Enlargement of PV outflow tract & 3 \\
VSD repair & 2 \\
Ductus ligation & 1 \\
ASD repair & 1
\end{tabular}

$A S D$, Atrial septal defect; $P V$, pulmonary ventricle; $V S D$, ventricular septal defect.

${ }^{*}$ Some patients had more than 1 previous procedure.

cally right ventricle remained the SV and the morphologically left ventricle was made the PV. The atrioventricular valves (AVVs) were assigned to either the SV or the PV.

Patients included were those operated on before 21 years of age from July 1, 1971, through January 31, 1996. Patient charts were reviewed, including results from cardiac catheterization, angiocardiography, and echocardiographic studies. Previous echocardiographic tapes, when available, were reviewed by one of the coauthors (H.M.C.). Preoperative echocardiographic studies were included if they were done within 100 days of the operation. Follow-up data were compiled from subsequent clinic visits, reports from physicians, results of patient questionnaires, and echocardiographic tapes from home physicians. The AVV connecting the morphologically left atrium with the (morphologically right) systemic ventricle (tricuspid valve) was designated as the systemic ventricle atrioventricular valve (SVAVV). The AVV connecting the morphologically right atrium with the (morphologically left) pulmonary ventricle (mitral valve) was designated as the pulmonary ventricle atrioventricular valve (PVAVV).

Data tabulated included age at operation, sex of the patients, and calendar year of operation. Associated defects were recorded, as well as the presence or absence of DORV and situs abnormalities. The number and type of previous operations, data on cardiac rhythm including need for pacemakers, and New York Heart Association (NYHA) classifications before the operation and at last follow-up were recorded. Perioperative data recorded included specific type of operative repair, postoperative complications, postoperative cardiac rhythm, and early mortality. Long-term followup data recorded included vital status, need for and type of reoperation, and date of last follow-up.

Assessment of ventricular function was derived solely from retrospective review of echocardiograms. Estimates of ventricular ejection fraction (EF) were analyzed as numerical data whenever possible. Early echocardiographic studies did not have numerical assessment of ventricular function. Therefore, all available echocardiograms were reviewed for qualitative assessment of ventricular function. Qualitative assessment of ventricular function was recorded as normal, mildly reduced, moderately reduced, and severely reduced. Ventricular function was considered normal when the EF was $55 \%$ or greater, mildly reduced (EF $40 \%-54 \%$ ), moderately reduced (EF 30\%-39\%), and severely reduced (EF 

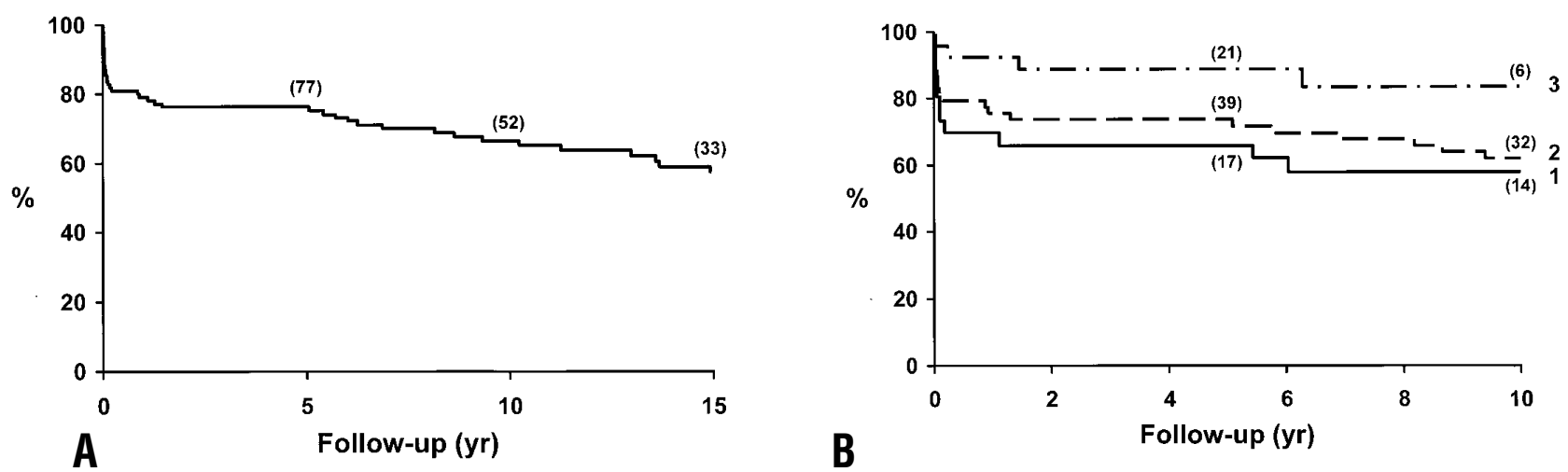

Figure 1. A, Kaplan-Meier survival curve for all 111 patients undergoing operation. There was a $16 \%$ mortality within 30 days. The 15 -year survival $( \pm S E)$ was $57 \%( \pm 5 \%)$. The number of patients at risk at each 5 -year interval is included in parentheses. B, Kaplan-Meier survival curves for all 111 patients stratified according to time interval of operation as shown in Table 4: group 1, 1971-1976; group 2, 1977-1986; group 3, 1987-1996. Five-year survivals for groups 1 to 3 were $67 \%( \pm 9 \%), 74 \%( \pm 6 \%)$, and $90 \%( \pm 6 \%)$, respectively. Analysis of the association between surgery year and survival showed improved survival for the more recent time intervals $(P=.04)$. The difference is due in large part to the difference in early mortality.

$29 \%$ or less). SV function was primarily evaluated in a qualitative fashion according to the ACC/AHA Practice Guidelines for the Clinical Application of Echocardiograms (1997). ${ }^{16 a}$

AVV insufficiency was also assessed from echocardiograms. Qualitative severity of AVV insufficiency was based on visual inspection combining variables of jet area, jet width, atrial size, venous flow, and AVV morphology.

Statistical methods evaluated various preoperative and perioperative factors that may have been associated with early and late mortality. Early mortality was defined as in-hospital death or death within 30 days of the index operation. Univariate associations with early mortality were evaluated on the basis of the $\chi^{2}$ test or the Fisher exact test for nominal or dichotomous scaled variables and based on the Wilcoxon rank sum test for ordinal or continuous scaled variables. Late mortality was defined as death after early survival. Survival estimates were calculated by means of the Kaplan-Meier method. Overall survival started at the index operation and late survival started 30 days after the index operation (there were no in-hospital deaths after 30 days). Univariate associations with patient survival were assessed on the basis of separate Cox regression models. Continuously scaled variables were assessed by means of single 1 degree of freedom terms, and categorical variables with $\mathrm{k}$ levels were assessed with the use of (K-1) dummy variables in the Cox regression models. The calendar year of index operation was categorized as 1971-1976, 1977-1986, and 1987-1996 and analyzed as an ordinal variable. The first interval (6 years, 1971-1976) began with the availability of extracardiac conduits, the second interval (10 years, 1977-1986) began with our use of cold cardioplegia, and the third interval (10 years, 1987-1996) constituted the most recent 10-year experience. A multivariable Cox regression model using a stepwise variable selection method was used to identify the set of factors most significantly associated with survival. All calculated $P$ values were 2 -sided.

\section{Patient Population}

A total of 111 patients were included in this study, 70 male and 41 female patients. The mean age at operation was 9.0 years with the range being 94 days to 20 years. The operation dates were from July 1, 1971, through January 31, 1996, with the median year of operation being 1980. Complex anatomy and situs abnormalities (defined as situs solitus of viscera and atria with isolated dextrocardia, situs inversus of viscera and atria with dextrocardia, or situs inversus of viscera and atria with isolated levocardia) were common. Thirty-eight (34\%) patients had situs abnormalities (Table 1). Forty-three (39\%) patients had DORV, and 29 (67\%) of those had situs abnormalities (Table 1).

Excluding pacemaker procedures, 49 patients had a total of 76 operations before conventional repair (Table 2). Fifty-nine (78\%) of the 76 procedures were done to improve pulmonary blood flow by some type of aorta-pulmonary artery shunt, formalin fixation of the ductus arteriosus, or enlargement of the PV outflow tract.

\section{Results}

The most common procedure performed at the time of repair was patch or suture closure of a VSD $(n=101)$. Other procedures performed are shown in Table 3.

Early mortality occurred in $18(16 \%)$ patients. The presence of a large VSD that necessitated closure with a patch, when compared with an intact ventricular septum or a small VSD that could be closed directly by suture, was strongly associated with early mortality $(P=.006$, Table 4$)$. Earlier calendar year of index operation was associated with early mortality $(P=.022)$; patients operated on since 1986 had a $3 \%$ early mortality, compared with $26 \%$ and $18 \%$ for $1971-$ 1976 and 1977-1986, respectively. Those patients who had 
TABLE 3. Repair procedures

\begin{tabular}{lc}
\hline Procedure & No. $^{*}$ \\
\hline Patch/suture closure of VSD & 101 \\
PV-PA conduit & 65 \\
Closure of ASD & 64 \\
Repair $(\mathrm{n}=1) /$ replacement $(\mathrm{n}=21$ ) of SVAVV & 22 \\
Relief of PV outflow tract obstruction & 8 \\
Ligation of patent ductus & 7 \\
Repair ( $=2$ )/replacement ( $=2$ ) of PVAVV & 4 \\
Replacement of aortic valve & 1
\end{tabular}

$A S D$, Atrial septal defect; $P A$, pulmonary artery; $P V$, pulmonary ventricle; PVAVV, pulmonary ventricle atrioventricular valve; SVAVV, systemic ventricle atrioventricular valve; $V S D$, ventricular septal defect.

*Some patients had more than 1 procedure at the time of repair.

a pacemaker before the operation or placed during the operation had no early mortality, but statistical analysis noted only a trend $(P=.069)$. There was also a trend for patients with more severe NYHA classification to have higher early mortality $(P=.094)$. Other factors analyzed included age at operation, previous operation, presence of DORV, presence of abnormal situs, preoperative PVAVV or SVAVV insufficiency, use of PV-pulmonary artery conduit, need for SVAVV or PVAVV repair or replacement, and preoperative cardiac rhythm (all had $P>.05)$. Overall survival $( \pm$ SE) for the entire group of 111 patients was $79 \%( \pm 4 \%)$ at 1 year, $77 \%( \pm 4 \%)$ at 5 years, $67 \%( \pm 5 \%)$ at 10 years, and $57 \%$ $( \pm 5 \%)$ at 15 years (Figure $1, A)$. Overall survival curves for each time interval of operation are shown in Figure 1, $B$.

Among the 93 early survivors, the mean length of follow-up was 11.4 years with the range being 45 days to 26.5 years. Fifty-two patients have had 10 or more years of follow-up. There have been 26 late deaths among the early survivors. By univariate analysis, previous operation (other than pacemaker placement) before repair was associated with late mortality $(P<.001)$. Survivors having no previous operation had a $90 \%( \pm 5 \%)$ 10-year survival (Table 5). Patients with more severe preoperative NYHA classification, abnormal cardiac situs, or preoperative cardiac rhythm other than normal sinus tended to have poorer survival; however, these univariate associations all had $P>.05$. Multivariable analysis identified previous operation (other than pacemaker placement) before conventional repair, more severe preoperative NYHA class, and preoperative cardiac rhythm other than normal sinus as factors independently associated with poorer survival $(P<$ $.05)$. Other factors analyzed included year of operation, age at operation, DORV, preoperative SVAVV and PVAVV insufficiency, VSD repair, PV-pulmonary artery conduit, previous or current pacemaker, and length of hospital stay (all had $P>.05$ ).
TABLE 4. Variables associated with early mortality

\begin{tabular}{|c|c|c|c|c|}
\hline \multirow[b]{2}{*}{ Variable } & \multirow[b]{2}{*}{ No. } & \multicolumn{2}{|c|}{$\begin{array}{c}\text { Early } \\
\text { mortality }\end{array}$} & \multirow[b]{2}{*}{$\begin{array}{l}P \text { value, univariate } \\
\text { analysis }\end{array}$} \\
\hline & & No. & $\%$ & \\
\hline \multicolumn{5}{|l|}{ VSD closure } \\
\hline None or suture repair & 26 & 0 & 0 & .006 \\
\hline Patch & 85 & 18 & 21 & \\
\hline \multicolumn{5}{|l|}{$\begin{array}{l}\text { Time interval of index } \\
\text { surgery }\end{array}$} \\
\hline $1971-1976$ & 27 & 7 & 26 & \\
\hline 1977-1986 & 55 & 10 & 18 & .022 \\
\hline 1987-1996 & 29 & 1 & 3 & \\
\hline \multicolumn{5}{|l|}{$\begin{array}{l}\text { Previous or operative } \\
\text { pacemaker }\end{array}$} \\
\hline Yes & 16 & 0 & 0 & .069 (trend) \\
\hline No & 95 & 18 & 19 & \\
\hline \multicolumn{5}{|l|}{ Preoperative NYHA class* } \\
\hline 1 & 13 & 0 & 0 & \\
\hline II & 74 & 13 & 18 & .094 (trend) \\
\hline III & 19 & 5 & 26 & \\
\hline
\end{tabular}

NYHA, New York Heart Association; VSD, ventricular septal defect.

*Preoperative NYHA class was not available for 5 patients.

\section{Pacemakers}

Pacemakers were commonly placed before the operation $(n=3)$ or at the time of the operation $(n=13)$. Within the first 30 days of operation, 10 additional patients had pacemakers placed. Subsequent need for pacemakers during later follow-up was also common. Among the 68 patients alive at 30 days without a pacemaker, an additional 8 required pacemakers during their follow-up; survival free of pacemaker placement was $89 \%( \pm 5 \%)$ at 10 years (Figure 2). At last follow-up, 19 (28\%) of 67 survivors have functioning pacemakers.

\section{Reoperations}

Reoperations other than pacemaker procedures were also common among the 93 early survivors; 38 (41\%) needed at least 1 additional operation. The 5-year survival free of reoperation was $81 \%( \pm 4 \%)$ (Figure 3$)$. Twenty-two patients have required conduit replacement for conduit stenosis, 13 needed SVAVV replacement $(n=9)$ or repair $(n=4)$ for progressive valve insufficiency, 6 needed repair of residual VSD, 4 needed PVAVV replacement $(n=2)$ or repair $(n=2)$ for valve insufficiency in conjunction with conduit replacement, 4 needed aortic valve repair or replacement, and 3 have undergone cardiac transplantation. There were no early deaths after reoperation other than in 1 patient who underwent cardiac transplantation elsewhere. 


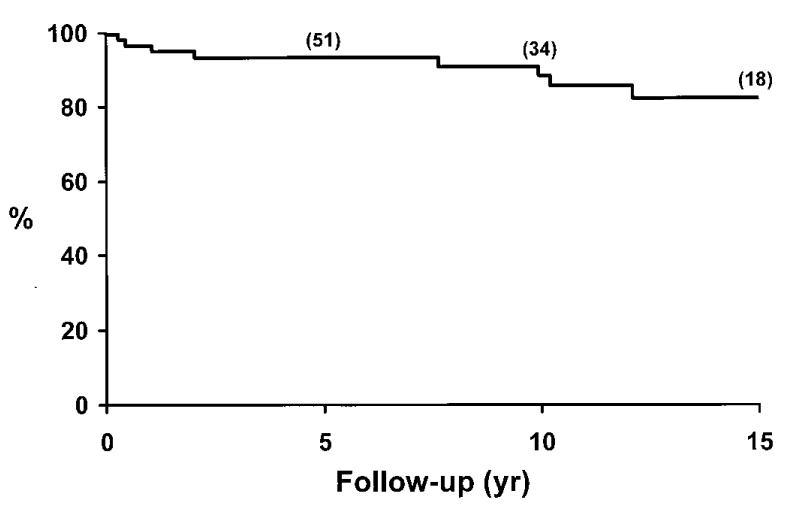

Figure 2. Kaplan-Meier curve for the 68 early survivors who were pacemaker-free showing survival free of subsequent pacemaker placement. Freedom from pacemaker placement at 10 years was $89 \%( \pm 5 \%)$.

\section{Ventricular Function}

Ventricular function data available for analysis included qualitative assessment of ventricular contractility by echocardiography as well as quantitative assessment by estimation of EF. Fifty-five patients had preoperative echocardiographic studies of SV function, which was normal in 30, mildly reduced in 16 , moderately reduced in 7 , and severely reduced in 2 . PV function was evaluated in 52 patients and was normal in 43 , mildly reduced in 6 , and severely reduced in 3 patients. The small numbers of patients with importantly reduced ventricular function precluded meaningful statistical analysis of risk for early and late death.

Thirty-six patients had both preoperative and pre-hospital discharge echocardiograms (SV, $P=.17$; PV, $P=1.00$; Wilcoxon signed rank test). Of 31 pre-discharge echocardiograms reviewed for SV function, the function was noted to be normal in 10 , mildly reduced in 15 , moderately reduced in 5, and severely reduced in 1 patient. Of 28 predischarge studies reviewed for PV function, function was normal in 23 and mildly reduced in 5 patients.

Forty-one patients had follow-up echocardiographic studies of SV function (range of follow-up, 24 days to 26 years); function was normal in 8 , mildly reduced in 23 , moderately reduced in 5, and severely reduced in 5 patients. Among 37 patients who had follow-up echocardiographic studies of PV function, function was normal in 25 , mildly reduced in 10 , moderately reduced in 1 , and severely reduced in 1 patient.

Data from patients who had EF estimated on a preoperative echocardiogram and also on a postoperative echocardiogram more than 1 year after surgery were analyzed. In the case of multiple follow-up echocardiograms, the most recent was used (Figure 4, $A$ and $B$ ). Mean preoperative SV EF was $49 \%$ and follow-up EF was $43 \%(\mathrm{n}=13)(P=.031)$.

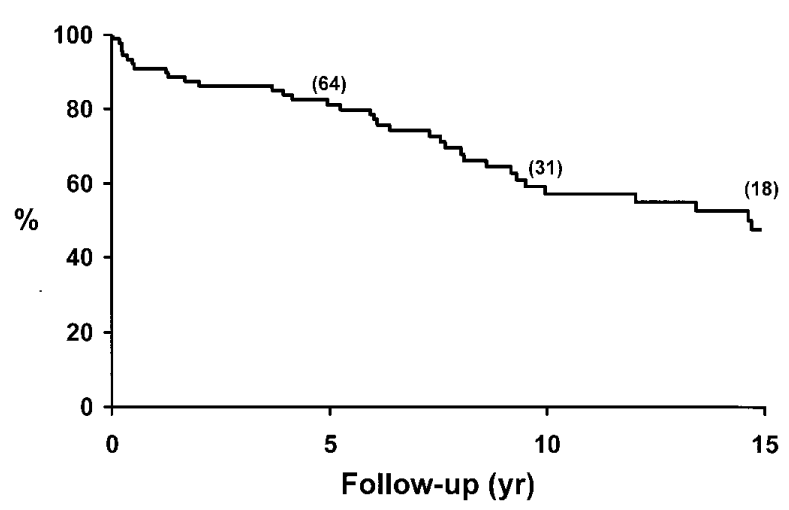

Figure 3. Kaplan-Meier curve for early survivors showing survival free of reoperation (other than for pacemaker placement). Freedom from reoperation was $81 \%( \pm 4 \%)$ at 5 years and $59 \%$ $( \pm 6 \%)$ at 10 years. The cumulative probability of having a reoperation by 10 years was $41 \%$.

Mean preoperative PV EF was $60 \%$ and follow-up EF was $62 \%(\mathrm{n}=10)(P=.39)$.

Nine patients among the early survivors had moderately or severely reduced preoperative SV function. These patients did not differ from other survivors with preoperative echocardiographic assessments with regard to calendar year of operation, previous operation, or length of hospital stay. However, the median age of the 9 with poor preoperative SV function was 13 years, compared with a median of 7 years for the 46 survivors with measured satisfactory function $(P=.009)$. Five of the 9 have required reoperation for repair or replacement of an SVAVV $(n=2)$, replacement of an obstructed conduit $(\mathrm{n}=$ $2)$, or replacement of an aortic valve $(n=1)$. Late echocardiographic studies were available for 5 of the 9 patients; 2 showed improvement in SV function of at least one functional category after operation and 3 showed no change. Four of the 9 remain alive at last follow-up. Although this group tended to have a relatively poor prognosis, the number of patients was too small to consider for statistical analysis.

\section{AVVs}

The associations between preoperative ventricular function and presence or absence of AVV insufficiency were analyzed. Preoperative SV EF and SVAVV insufficiency were compared for 33 patients for whom data were available. Twenty-one (64\%) patients had no insufficiency, trivial, or mild SVAVV insufficiency, and their mean EF was $49 \%$. Twelve $(36 \%)$ patients had moderate or severe SVAVV insufficiency, and their mean EF was slightly lower (46\%) $(P=.50)$. Preoperative PV EF and degree of PVAVV insufficiency were compared for 24 patients for whom data were available. All 24 patients had no insufficiency, trivial, or mild PVAVV insufficiency, and their mean EF was 55\%. 

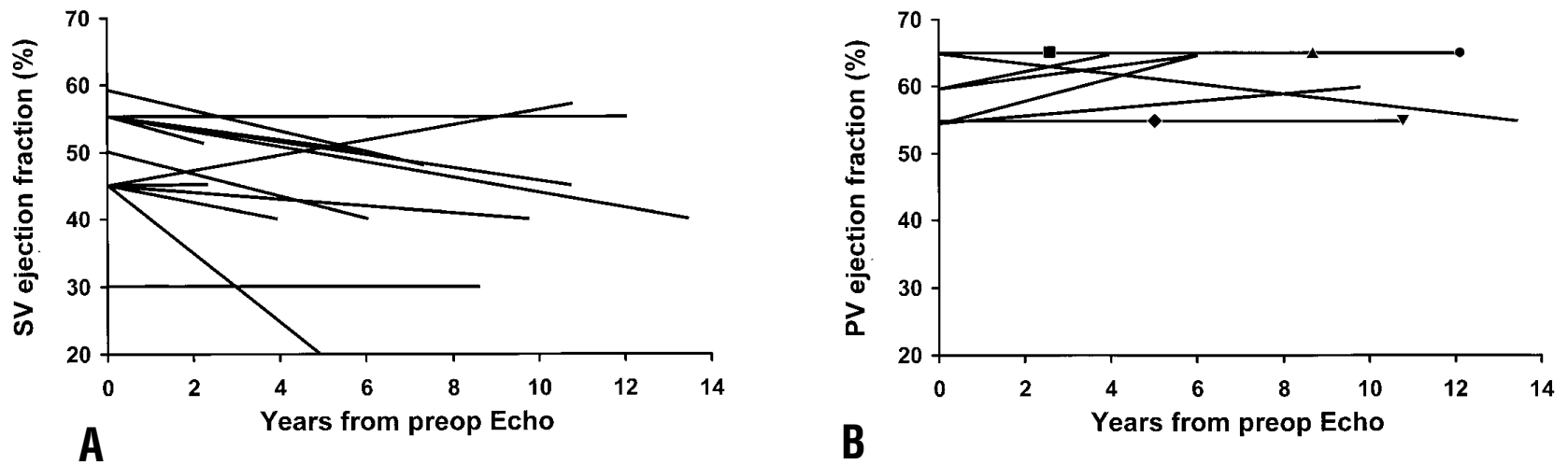

Figure 4. A, Comparison of preoperative systemic ventricle (SV) ejection fraction (time 0 ) and postoperative ejection fraction at time of last echocardiogram (at least 1 year later) (mean, $49 \%$ vs $43 \% ; P=.031$ ). B, Comparison of preoperative pulmonary ventricle (PV) ejection fraction (time 0 ) and postoperative ejection fraction at time of last echocardiogram (at least 1 year later) (mean, 60\% or 62\%). Three patients share the top line with follow-up at 2.6, 8.7, and 12.2 years. Two other patients share the bottom line with follow-up at 4.9 and 11 years.

TABLE 5. Variables associated with late mortality

\begin{tabular}{|c|c|c|c|c|c|c|c|}
\hline \multirow[b]{2}{*}{ Variable } & \multirow[b]{2}{*}{ No. } & \multicolumn{2}{|c|}{$\% 5$-year survival } & \multicolumn{2}{|c|}{$\%$ 10-year survival } & \multicolumn{2}{|c|}{$P$ value } \\
\hline & & Rate \pm SE & No. at risk & Rate \pm SE & No. at risk & $\begin{array}{l}\text { Univariate } \\
\text { analysis }\end{array}$ & $\begin{array}{c}\text { Multivariate } \\
\text { analysis }\end{array}$ \\
\hline \multicolumn{8}{|c|}{ Previous operation (pacemakers excluded) } \\
\hline Yes & 39 & $82 \pm 6$ & 30 & $65 \pm 8$ & 17 & \multirow[t]{2}{*}{$<.001$} & \multirow[t]{2}{*}{$<.001$} \\
\hline No & 54 & $96 \pm 3$ & 46 & $90 \pm 5$ & 35 & & \\
\hline \multicolumn{8}{|c|}{ Preoperative NYHA class* } \\
\hline I & 13 & $100 \pm-$ & 13 & $92 \pm 8$ & 10 & \multirow{3}{*}{.062 (trend) } & \multirow{3}{*}{.033} \\
\hline II & 61 & $92 \pm 4$ & 49 & $83 \pm 5$ & 33 & & \\
\hline III & 14 & $86 \pm 9$ & 12 & $62 \pm 14$ & 7 & & \\
\hline \multicolumn{8}{|c|}{ Preoperative cardiac rhythm } \\
\hline Sinus & 84 & $92 \pm 3$ & 70 & $83 \pm 5$ & 49 & \multirow[t]{2}{*}{.084 (trend) } & \multirow[t]{2}{*}{.035} \\
\hline Other & 9 & $78 \pm 14$ & 6 & $52 \pm 18$ & 3 & & \\
\hline \multicolumn{8}{|c|}{ Abnormal cardiac situs } \\
\hline Yes & 34 & $82 \pm 7$ & 27 & $73 \pm 8$ & 19 & \multirow[t]{2}{*}{.059 (trend) } & \multirow[t]{2}{*}{$>.05$} \\
\hline No & 59 & $95 \pm 3$ & 49 & $84 \pm 5$ & 33 & & \\
\hline
\end{tabular}

*Preoperative NYHA class was not available for 5 patients.

The association between degree of AVV insufficiency and type of cardiac anatomy was also analyzed. The presence of DORV was favorably associated with a lesser degree of SVAVV insufficiency $(P=.003)$. Of 43 patients with DORV, 23 had no insufficiency, mild, or trivial insufficiency, 3 had moderate insufficiency, and only 1 had severe SVAVV insufficiency (in 16 the degree of insufficiency was unknown). Of 68 patients without DORV, 26 had no insufficiency, mild, or trivial insufficiency, 3 had moderate, and 19 had severe SVAVV insufficiency (in 20 the degree of insufficiency was unknown).

AVV status was analyzed among early survivors to assess the tendency for progression of insufficiency. Data were reviewed on 14 patients who had no or trivial SVAVV insufficiency at preoperative assessment, survived the operation, and had a follow-up assessment at least 1 year after the operation (mean follow-up, 9.0 years). Only 2 patients remained free of SVAVV insufficiency on follow-up. Five patients had mild, 5 moderate, and 2 severe SVAVV insufficiency on follow-up. Data were also reviewed on 13 patients who had no or trivial PVAVV insufficiency at preoperative assessment (mean follow-up, 10.1 years). Six of these continued to have no or trivial PVAVV insufficiency, but 3 had mild, 3 had moderate, and 1 had severe PVAVV insufficiency. 


\section{Discussion}

To our knowledge, this series of 111 patients represents the largest experience and longest follow-up of operations for corrected TGA reported for the pediatric age group. The frequency of situs abnormalities and DORV (Table 1) with corrected TGA in these patient represents an experience that is equal to or more complex than other series. ${ }^{1-4}$

The overall early mortality of $16 \%$ and the more recent early mortality of $3 \%$ (95\% confidence intervals, $0.1 \%$ $17.8 \%$ ) compare favorably with published reports. ${ }^{1-4}$ Important risk factors for early mortality were found to be patch repair of a large VSD and earlier calendar year of index operation. These findings have not been emphasized in previous reports. The small number of patients with moderate or severe reduction in ventricular function in this series precluded evaluation of ventricular function as a risk factor.

In previous reports from our institution, we had noted that development of complete heart block at the time of operation was associated with a higher early mortality. ${ }^{17,18}$ Such an association was not observed in this series. Current refinements in techniques for avoiding injury to the conduction bundle during closure of the VSD and during relief of PV outflow tract obstruction have led to a lower incidence of perioperative heart block. ${ }^{19-23}$

Risk factors for late mortality included more severe preoperative NYHA class, need for previous operation, and preoperative cardiac rhythm other than sinus rhythm. These findings are unique to this report.

There is evidence for poorer prognosis for patients at older age at the index operation if preoperative SV function has been reduced. This finding suggests earlier operation may be indicated for those with impaired SV function.

The need for repair or replacement of the SVAVV was common both at the index operation and at reoperation, but SVAVV insufficiency was not found to be a risk factor for early or late mortality in this pediatric cohort. This observation differs from other reports that include patients of all ages. ${ }^{24-26}$ Abnormalities of the SVAVV (morphologically tricuspid valve) in corrected transposition are so common that they may be considered an intrinsic part of the pathophysiology of this condition. $8,24,27$ There are often severe dysplastic changes in the leaflets, and the septal and posterior leaflets may be displaced in a "left-sided" Ebstein-type of anomaly. 8,28 In our experience, significant SVAVV insufficiency is best treated by valve replacement rather than valve repair.

In a recent report from our institution in which patients over the age of 20 years were not excluded, ${ }^{24}$ the early and late mortality were both associated with an SV EF of less than $44 \%$. This was not found in this series of pediatric patients. Ventricular function, especially SV function, can clearly deteriorate with time in some patients with corrected TGA, as noted in this review; three patients in this series ultimately required cardiac transplantation. SVAVV insufficiency and SV dysfunction are closely interrelated. ${ }^{24}$ Accordingly, all survivors should have appropriate follow-up visits with particular attention to SVAVV competence, SV function, and cardiac rhythm. Patients with corrected TGA may have the same longterm outlook as patients who have had the Senning or Mustard operations, ${ }^{29}$ but our follow-up period has not been long enough to address this.

Complete heart block was commonly encountered preoperatively, perioperatively, and at follow-up. This finding is consistent with the previous observation by Huhta and colleagues, ${ }^{27}$ who noted a significant rate of spontaneous heart block in patients with corrected TGA over time. The fact that almost one third of current survivors have a functioning pacemaker is similar to at least one previous report. ${ }^{3}$

The cumulative probability of having a reoperation by 10 years was $41 \%$, and this is similar to that of published reports. ${ }^{3}$ Fortunately, the need for reoperation did not affect late survival statistics in this series, as there was no early mortality associated with reoperation except for 1 patient who died after cardiac transplantation. Primary reasons for reoperation included AVV insufficiency and residual/recurrent VSD, as noted in other reports. ${ }^{1,3}$ The need for late reoperation for AVV insufficiency, especially SVAVV insufficiency, suggests that, for some patients, AVV insufficiency is progressive. Similar observations have been made by others. ${ }^{24,25}$

Advocates of the double-switch procedure (atrial switch [Mustard or Senning] plus arterial switch) or atrial switch plus a modified Rastelli operation have cited concerns regarding SV function and late morbidity and mortality as reasons for undertaking these newer approaches. ${ }^{6-8}$ There is a compelling theoretical advantage to making the morphologically left ventricle the SV. There may be less need for reoperation for replacement of the morphologically tricuspid valve, which would function under lower (pulmonary) pressure after a double-switch procedure. In our experience, these operations require a longer operating time, which may adversely affect early morbidity and mortality. They would be vulnerable to the known late complications of atrial and arterial switches and Rastelli procedures as well. The progressive need for pacemaker placement in patients with corrected TGA would probably not be affected by the newer procedures.

This report of early and long-term results in a large series of patients who have undergone conventional operations for the defects associated with corrected TGA should serve as a basis for comparison with newer surgical alternatives.

We are indebted to Beth G. Scherer, MS, Department of Biostatistics, for valuable help with the statistical analyses and to Merrilee S. Rogotzke and Lenore M. Bille for excellent secretarial support. 


\section{References}

1. McGrath LB, Kirklin JW, Blackstone EH, Pacifico AD, Kirklin JK, Bargeron LM Jr. Death and other events after cardiac repair in discordant atrioventricular connection. J Thorac Cardiovasc Surg. 1985;90:711-28.

2. Lundstrom U, Bull C, Wyse R, Somerville J. The natural and "unnatural" history of congenitally corrected transposition. Am J Cardiol. 1990;65:1222-9.

3. Sano T, Riesenfeld T, Karl TR, Wilkinson JL. Intermediate-term outcome after intracardiac repair of associated cardiac defects in patients with atrioventricular and ventriculoarterial discordance. Circulation. 1995;92(Suppl):II-272-8.

4. Termignon JL, Leca F, Vouhé PR, Vernant F, Bical OM, Lecompte Y, et al. "Classic" repair of congenitally corrected transposition and ventricular septal defect. Ann Thorac Surg. 1996;62:199-206.

5. Freed MD, Colli AM, Lock JE, Jonas RA, Mayer JE, Castaneda A. Long-term follow up of patients with corrected transposition, ventricular septal defect and pulmonary stenosis. Proc World Cong Pediatr Cardiol Pediatr Card Surg. 1993;3:57.

6. Karl TR, Weintraub RG, Brizard CP, Cochrane AD, Mee RBB. Senning plus arterial switch operation for discordant (congenitally corrected) transposition. Ann Thorac Surg. 1997;64:495-502.

7. Reddy VM, McElhinney DB, Silverman NH, Hanley FL. The double switch procedure for anatomical repair of congenitally corrected transposition of the great arteries in infants and children. Eur Heart J. $1997 ; 18: 1470-7$

8. Van Praagh R, Papagiannis J, Grünenfelder J, Bartram U, Martanovic P. Pathologic anatomy of corrected transposition of the great arteries: medical and surgical implications. Am Heart J. 1998;135:772-85.

9. Graham TP Jr, Parrish MD, Boucek RJ Jr, Boerth RC, Breitwiser JA, Thompson S, et al. Assessment of ventricular size and function in congenitally corrected transposition of the great arteries. Am J Cardiol. 1983,51:244-51

10. Benson LN, Burns R, Schwaiger M, Schelbert HR, Lewis AB, Freedom RM, et al. Radionuclide angiographic evaluation of ventricular function in isolated congenitally corrected transposition of the great arteries. Am J Cardiol. 1986;58:319-24.

11. Dimas AP, Moodie DS, Sterba R, Gill CC. Long-term function of the morphologic right ventricle in adult patients with corrected transposition of the great arteries. Am Heart J. 1989;118:526-30.

12. Connelly MS, Liu PP, Williams WG, Webb, GD, Robertson P, McLaughlin PR. Congenitally corrected transposition of the great arteries in the adult: functional status and complications. $J$ Am Coll Cardiol. 1996;27:1238-43.

13. Presbitero P, Somerville J, Rabajoli F, Stone S, Conte MR Corrected transposition of the great arteries without associated defects in adult patients: clinical profile and follow up. Br Heart J. 1995;74:57-9.

14. Connolly HM, Grogan M, Warnes CA. Pregnancy among women with congenitally corrected transposition of the great arteries. $J$ Am Coll Cardiol. 1999;33:1692-5.

15. Kiser JC, Ongley PA, Kirklin JW, Clarkson PM, McGoon DC. Surgical treatment of dextrocardia with inversion of ventricles and double-outlet right ventricle. J Thorac Cardiovasc Surg. 1968;55:6-15.

16. Tabry IF, McGoon DC, Danielson GK, Wallace RB, Davis Z, Maloney JD. Surgical management of double-outlet right ventricle associated with atrioventricular discordance. J Thorac Cardiovasc Surg. 1978;76:336-44

16a. American College of Cardiology/American Heart Association Task Force on Practice Guidelines. ACC/AHA guidelines for the clinical application of echocardiography: executive summary. $J$ Am Coll Cardiol. 1997;29:862-79.

17. Bonfils-Roberts EA, Guller B, McGoon DC, Danielson GK. Corrected transposition: surgical treatment of associated anomalies. Ann Thorac Surg. 1974;17:200-9.

18. Marcelletti C, Maloney JD, Ritter DG, Danielson GK, McGoon DC, Wallace RB. Corrected transposition and ventricular septal defect: surgical experience. Ann Surg. 1980;191:751-9.

19. Anderson RH, Danielson GK, Maloney JD, Becker AE. Atrioventricular bundle in corrected transposition. Ann Thorac Surg. 1978;26:95-6.

20. Danielson GK, McGoon DC, Wallace RB, Fiddler GI, Maloney JD. Surgery of corrected transposition. In: Anderson RH, Shinebourne EA, editors. Pediatric cardiology. Edinburgh: Churchill Livingstone; 1978. p. 224-30

21. de Leval MR, Bastos P, Stark J, Taylor JF, Macartney FJ, Anderson $\mathrm{RH}$. Surgical technique to reduce the risks of heart block following closure of ventricular septal defect in atrioventricular discordance. $J$ Thorac Cardiovasc Surg. 1979;78:515-26.

22. Danielson GK. Surgical treatment of atrioventricular discordance. In: Losekoot TG, Anderson RH, Becker AE, Danielson GK, Soto B, editors. Congenitally corrected transposition. Edinburgh: Churchill Livingstone; 1983. p. 177-90.

23. Russo P, Danielson GK, Driscoll DJ. Transaortic closure of ventricular septal defect in patients with corrected transposition with pulmonary stenosis or atresia. Circulation. 1987;76(Suppl):III-88-92.

24. van Son JAM, Danielson GK, Huhta JC, Warnes CA, Edwards WD, Schaff $\mathrm{HV}$, et al. Late results of systemic atrioventricular valve replacement in corrected transposition. J Thorac Cardiovasc Surg. 1995; 109:642-53.

25. Voskuil M, Hazekamp MG, Kroft LJ, Lubbers WJ, Ottenkamp J, van der Wall EE, et al. Postsurgical course of patients with congenitally corrected transposition of the great arteries. Am $J$ Cardiol. 1999;83:558-62

26. Acar P, Sidi D, Bonnet D, Aggoun Y, Bonhoeffer P, Kachaner J. Maintaining tricuspid valve competence in double discordance: a challenge for the paediatric cardiologist. Heart. 1998;80:479-83.

27. Huhta JC, Danielson GK, Ritter DG, Ilstrup DM. Survival in atrioventricular discordance. Pediatr Cardiol. 1985;6:57-60.

28. Anderson KR, Zuberbuhler JR, Anderson RH, Becker AE, Lie JT. Morphologic spectrum of Ebstein's anomaly of the heart: a review. Mayo Clin Proc. 1979;54:174-80.

29. Myridakis DJ, Ehlers KH, Engle MA. Late follow-up after venous switch operation (Mustard procedure) for simple and complex transposition of the great arteries. Am J Cardiol. 1994;74:1030-6. 